\title{
PELATIHAN DAN PENDAMPINGAN PENGGUNAAN APLIKASI EDMODO SEBAGAI PENUNJANG KEGIATAN BELAJAR MENGAJAR DI KALANGAN GURU SMP NEGERI 3 KALIMANAH
}

\author{
Khairunnisak Nur Isnaini, Siti Alvi Solikhatin, Ali Nur Ikhsan dan Pungkas Subarkah ${ }^{1}$ \\ ${ }^{1}$ Fakultas Ilmu Komputer Universitas Amikom Purwokerto \\ e-mail: subarkah@ amikompuwokerto.ac.id
}

\begin{abstract}
Abstrak
Saat ini perkembangan teknologi informasi berjalan begitu cepat. Hadirnya terknologi informasi berperan dalam berbagai aspek kehidupan salah satunya bidang pendidikan. Hal tersebut berpengaruh terhadap kesiapan sekolah dalam memaksimalkan performanya agar kegiatan belajar mengajar dapat dilaksanakan secara optimal. Salah satunya yaitu kesiapan para pengajar dalam memanfaatkan berbagai macam bentuk teknologi informasi. Tujuan pengabdian ini adalah melatih serta mendampingi guru dalam penggunaan aplikasi edmodo sehingga dapat diimplementasikan para guru dalam kegiatan belajar mengajar di sekolah. Hasil dari pengabdian ini adalah ilmu dalam penggunaan aplikasi edmodo. sehingga diharapkan kedepannya guru-guru SMP Negeri 3 Kalimanah menggunakan aplikasi tersebut dalam menunjang kegiatan belajar mengajar.
\end{abstract}

Kata Kunci: Edmodo, Kegiatan Belajar Mengajar

\section{A. Pendahuluan}

Kegiatan Belajar Mengajar saat ini di sekolah menurut paparan yang disampaikan oleh Wakil Menteri Pendidikan pada Konsep dan Implementasi Kurikulum 2013 antara lain Observing, Questioning, Associating, Experementing, Creating, Networking, Commnucating, dan Implementing. Kegiatan Belajar Mengajar tersebut dibungkus ke dalam konsep kurikulum yang harus menyeimbangkan Standar Kompetensi Lulusan, Standar Isi, Standar Proses, dan Standar Penilaian. Buku-buku yang digunakan dikelompokkan menjadi buku guru dan buku siswa. Buku siswa dikhususkan untuk menjadi buku kegiatan siswa. Hal ini tentu menuntut kreativitas peran guru dalam menyampaikan keseluruhan materi yang diajarkan termasuk peran teknologi informasi yang dapat membantu kelancaran proses kegiatan belajar mengajar.

Media pembelajaran adalah salah satu metode dalam mengatasi segala macam persoalan dalam mengajar, bukan saja mengatasi persoalan, namun media pemberi pembelajaran memberi berbagai informasi yang koprehensip kepada peserta didik(Tafonao, 
2018). E-learning adalah penggunaan teknologi komputer jaringan, melalui intranet atau internet, untuk mengirimkan informasi dan instruksi kepada individu(Elizabeth T. Welsh, Connie R. Wanberg, 2003). Dalam penggunaan aplikasi edmodo digunakan sebagai media penunjang kegiatan belajar mengajar. Hal ini tentunya didukung dari adanya internet ataupun kegiatan belajar secara daring / online atau disebut dengan pembelajaran e-learning. e-learning menawarkan metode baru untuk pembelajaran jarak jauh berbasis komputer dan teknologi(Tsvetozar Georgiev, Evgenia Georgieva, 2004).

Saat ini teknologi informasi berperan dalam berbagai bidang khususnya pada bidang pendidikan. Tentunya materi teknologi informasi pun masuk ke dalam materi sertifikasi guru atau pendidikan kilat yang telah di selenggarakan pemerintah sampai saat ini khususnya pada pemanfaatan teknologi informasi sebagai penunjang kegiatan belajar mengajar. Berdasarkan Data Pokok Pendidikan Dasar dan Menengah Kementerian Pendidikan dan Kebudayaan, guru-guru SMP Negeri 3 Kalimanah lebih dari 50\% telah menempuh sertifikasi. Artinya, hampir keseluruhan guru telah memahami pemanfaatan teknologi informasi sebagai media penunjang kegiatan belajar.

Namun faktanya tidak semua guru dapat memahami atau mengerti pemanfaatan teknologi informasi yang saat ini sedang berkembang sedangkan hal tersebut cukup menjadi tuntutan guru sebagai pengajar. Seorang guru tidak dituntut untuk membuat media kegiatan belajar mengajar untuk siswa-siswinya namun harus dapat memanfaatkan aplikasi dalam menunjang kegiatan belajar mengajarnya.

\section{B. Masalah}

Melihat kondisi guru yang ada di SMP Negeri 3 Kalimanah Kabupaten Purbalingga, yang menjadi permasalahan adalah:

1. Bagaimana cara menggunakan aplikasi edmodo dengan benar.

2. Pengetahuan guru dengan adanya teknologi informasi sangat minim.

\section{Metode Pelaksanaan}

Metode yang digunakan dalam melaksanakan kegiatan ini adalah dengan mendapatkan data dengan melakukan wawancara dengan Kepala Sekolah SMP Negeri 3 Kalimanah. Penyampaaian materi yang di gunakan dengan cara ceramah dan workshop dalam pembuatan akun aplikasi edmodo. Peserta pelatihan diberikan penjelasan 
tentang dasar penggunaan edmodo baik menggunakan website dan berbasis android. Pengisian konten yang ada didalam edmodo, diantara soal tugas pilihan ganda ataupun soal essai. Tahap selanjutnya adalah workshop dalam penggunaan aplikasi edmodo dengan teori dan di lanjutkan dengan praktik dalam penggunaan edmodo menggunakan website dan berbasis android.

Rangkaian kegiatan pengabdian masyarakat adalah sebagai berikut:

1. Tahap Persiapan

Pada tahapan ini, meliputi:

a) Persiapan kelegkapan administrasi, surat menyurat, surat izin, bahan materi dan software pendukung.

b) Persiapan media dan fasilitas penunjang

c) Persiapan undangan peserta pelatihan, banner, power point dan modul materi pelatihan

d) Persiapan tim pengabdian masyarakat dengan membagi tugas dan tanggung jawab

e) Metode, meliputi:

1) Studi Literatur

2) Wawancara

3) Diskusi

f) Penetapan lokasi pelatihan di SMP Negeri 3 Kalimanah

2. Tahap Pelaksanaan

Pada tahapan pelaksanaan pelatihan, yaitu teknis dalam penyampaian materi pelatihan dan pendampingan, meliputi:

a. Pembukaan

b. Penyampaian materi pengantar

1) Penjelasan tentang kegunaan aplikasi edmodo

2) Pengenalan aplikasi edmodo untuk kalangan guru

c. Penyampaian materi teknis

1) Penjelasan tentang pembuatan akun edmodo bagi guru

2) Cara pengisian konten, deskripsi dan soal, dan lain-lain.

d. Workshop penggunaan aplikasi edmodo

1) Penjelasan implementasi aplikasi edmodo untuk kegiatan belajar mengajar

2) Praktik dengan menggunakan smartphone berbasis android dan berbasis website dalam penggunaan aplikasi edmodo. 
e. Metode dalam proses tahapan pelaksanaan, meliputi:

1) Diskusi.

2) Ceramah. Kegiatan penyuluhan dilakukan dengan ceramah dan diskusi sekaligus praktek lapangan (LODM Mustari, dkk., 2019:37).

3) Workshop.

4) Tanya jawab.

\section{Tahap Evaluasi}

Pada tahapan evaluasi ini, meliputi:

a. Evaluasi hasil pelatihan dan pendampingan

b. Metode dalam tahap evaluasi yaitu diskusi dan tanya jawab.

\section{Pembahasan}

1. Persiapan

Tahap kegiatan yang pertama dalam kegiatan pengabdian ini adalah tahap persiapan. Tahap persiapan berjalan sesuai dengan rencana yang telah dirancang oleh tim pengabdian. Tindakan dalam tahapan ini yaitu implementasi program penggunaan aplikasi edmodo bagi kalangan guru SMP Negeri 3 Kalimanah. Tahapan persiapan dilakukan untuk menemukan permasalahan yang berkaitan dengan pembelajaran berbasi online atau yang disebut dengan e-learning, khususnya dalam penggunaan aplikasi edmodo. Dari hasil observasi dilapangan maka diperoleh data bahwa fasilitas untuk pembelajar e-learning di SMP Negeri 3 Kalimanah sudah cukup memadai. Fasilitas yang dimaksudkan yaitu berupa fasilitas hostpot, LCD di ruang kelas. Namun dengan fasilitas yang memadai di sekolah tersebut, belum dioptimalkan oleh guru-guru karena minim pengetahuan tentang penggunaan teknologi informasi khususnya penggunaan aplikasi edmodo guna menunjang kegiatan belajar mengajar. Oleh karena itu, kegiatan pelatihan penggunaan aplikasi edmodo ini sangat penting dan tepat untuk guru-guru di SMP Negeri 3 Kalimanah agar proses pembelajaran lebih optimal sehingga siswa dapat memahami materi dengan baik.

2. Pelaksanaan

Tahap kedua dalam kegiatan pengabdian ini adalah tahap pelaksanaan. Kegiatan pertama yang dilakukan adalah pembuatan akun edmodo. Akun dapat dibuat menggunakan akun gmail maupun dapat langsung log-in menggunakan akun gmail yang dimiliki oleh perserta. Kedua, peserta diarahkan untuk mengetahui menu-menu dan fungsi yang ada di 
dalam edmodo. Ketiga, peserta diarahan untuk berlatiha membuat postingan materi baik ditulis langsung maupun diunggah dari sumber data (source file) yang ada di laptop masingmasing. Keempat, perserta diarahkan untuk mulai membuat soal kuis atau dapat dikatakan seperti soal ulangan dengan beragam fungsi dan variasi antara lain soal dengan tipe pilihan ganda, mencocokan jawaban, isian pendek, dan uraian. Fungsi-fungsi yang ada di dalam pembuatan soal seperti pengacakan soal, pembatasan soal ketika di akses, dan melihat hasil maupun nilai yang diperoleh siswa-siswinya.

Narasumber dalam pelatihan ini adalah Siti Alvi Solikhatin, M.Kom., yang dibantu dengan tim pengabdian lainnya. Dalam penyampaian materi berikut dengan bimbingan pelatihan dan pendampingan kepada guru-guru SMP Negeri 3 Kalimanah. Narasumber dan tim pengabdian merupakan Dosen pada Universitas Amikom Purwokerto. Pelaksanaan kegiatan pelatihan dan pendampingan penggunaan aplikasi edmodo di SMP Negeri 3 Kalimanah dibagi menjadi 2 sesi, pada sesi pertama yaitu penyampaian materi pengenalan aplikasi edmodo dan pada sesi kedua yaitu tentang materi teknis didalam penggunaan aplikasi edmodo untuk penunjang kegiatan belajar mengajar.

3. Evaluasi

Tahap ketiga dalam kegiatan pengabdian ini yaitu tahap evaluasi. Dimana tahap ini bertujuan untuk mengetahui bagaimana selama kegiatan pengabdian ini berlangsung. Kegiatan pengabdian yang dilaksanakan bagi guru-guru di SMP Negeri 3 Kalimanah telah berlangsung dengan baik Antusias guru dalam proses pelaksanaan pelatihan pengunaan aplikasi edmodo dan sambutan positif bahwa kegiatan ini berdampak baik bagi guru-guru untuk kedepannya karena menggunakan teknologi dalam proses belajar dan mengajar.

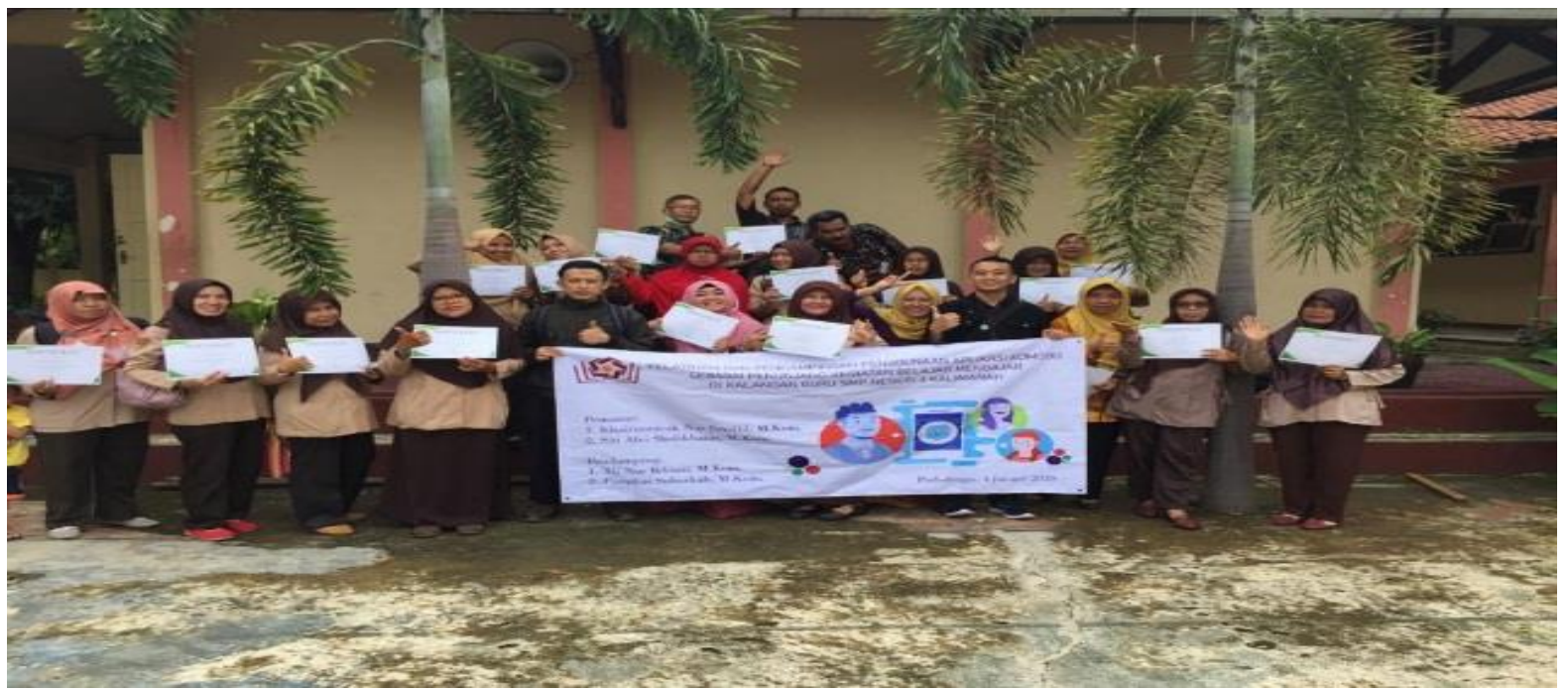




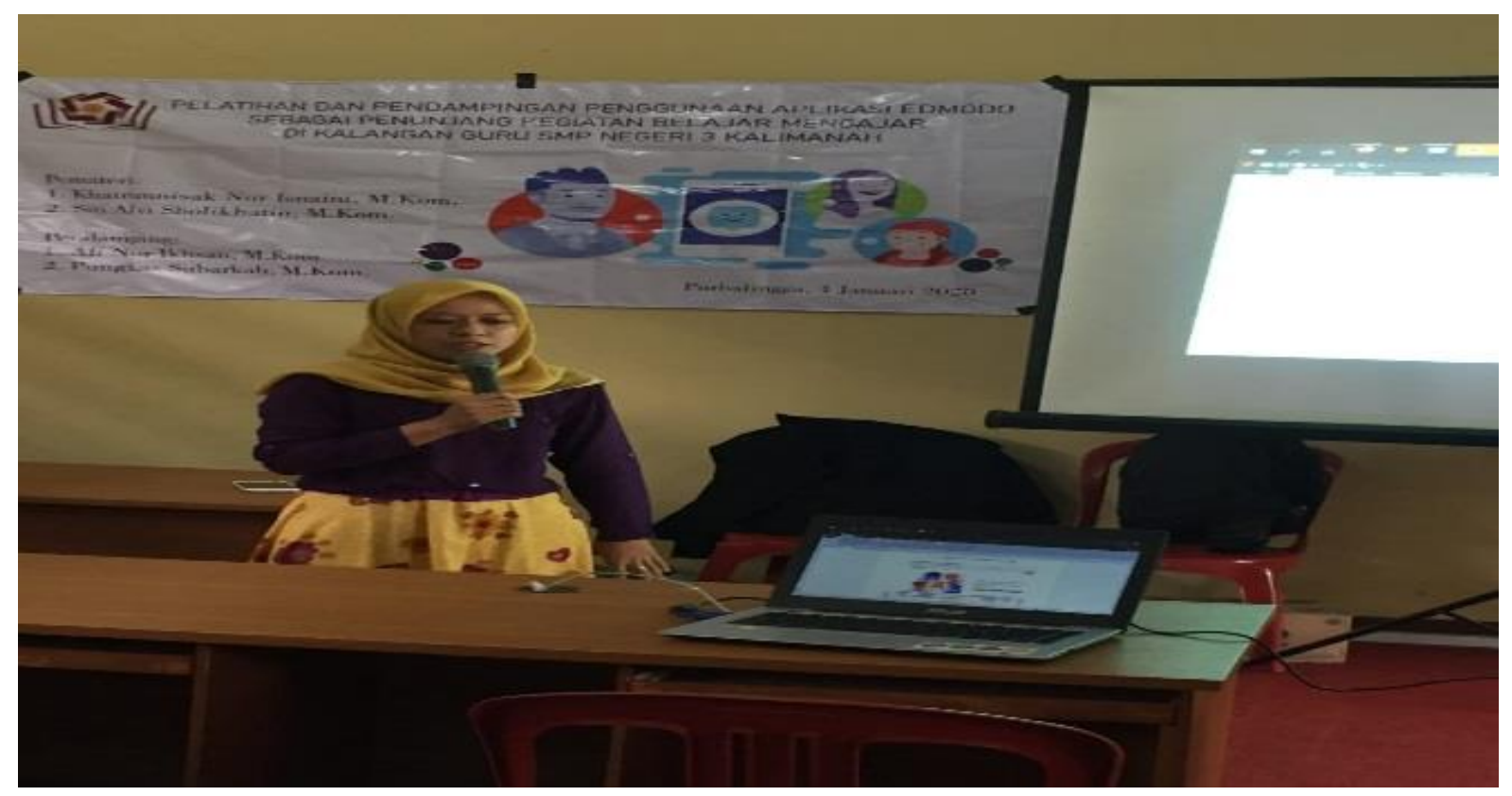

Gambar 1. Pelaksanaan Pelatihan dan Pendampingan Penggunaan Aplikasi Edmodo

\section{E. Kesimpulan}

Berdasarkan hasil dan pembahasan yang sudah disampaikan pada pelaksanaan pengabdian masyarakat mengenai pelatihan dan pendampingan penggunaan aplikasi edmodo sebagai penunjang kegiatan belajar mengajar di kalangan guru SMP Negeri 3 Kalimanah, diambil kesimpulan sebagai berikut: (1) Meningkatkan wawasan guru-guru di SMP Negeri 3 Kalimanah akan adanya aplikasi mapun website yang dapat membantu kegiatan belajar mengajar di sekolah; (2) Meningkatkan kemampuan guru-guru di SMP Negeri 3 Kalimanah dalam mengoperasikan sebuah website maupun aplikasi khususnya di dalam lingkup pendidikan seperti Edmodo; (3) Meningkatkan awareness tentang pentingnya menjaga akun dan password email yang sedang digunakan sebagai pintu masuk ke hampir semua akses aplikasi maupun website; (4) Edmodo terbukti dapat membantu guru-guru untuk meningkatkan atau menambah wawasan dalam mengetahui beragam variasi metode kegiatan belajar mengajar bagi siswa-siswi di SMP N 3 Kalimanah melalui fitur-fitur yang disediakan seperti pembuatan kuis, aturan-aturan yang dapat dipilih guru untuk membuat soal ulangan, maupun sekadar untuk mengunggah materi pelajaran; (5) Handbook tutorial Edmodo yang dibuat oleh tim pengabdian turut membantu lancarnya penggunaan Edmodo oleh guru-guru di SMP N 3 Kalimanah pada saat terlaksanakanya kegiatan pelatihan dan pendampingan. 


\section{DAFTAR PUSTAKA}

Elizabeth T. Welsh, Connie R. Wanberg, K. G. B. and M. J. S. (2003). E-learning: emerging uses,empirical results and future directions. International Journal of Training and Development.

LODM Mustari, Antasalam Ajo, Azelia Monica A, Hardin. (2019). Penyuluhan Laboratorum Lapangan Budidaya Terong Dan Cabe di Kelurahan Bandar Batauga Kecamatan Batauga Kabupaten Buton Selatan. Jurnal Pengabdian Kepada Masyarakat MEMBANGUN NEGERI, 3(2), 36-47.

Tafonao, T. (2018). Peranan Media Pembelajaran Dalam Meningkatkan Minat Belajar Mahasiswa. Jurnal Komunikasi Pendidikan, 2(2).

Tsvetozar Georgiev, Evgenia Georgieva, A. S. (2004). M-Learning-a New Stage of ELearning. International Conference on Computer Systems and Technologies. 